\title{
Improvement in cerebral hemodynamic parameters and outcomes after superficial temporal artery- middle cerebral artery bypass in patients with severe stenoocclusive disease of the intracranial internal carotid or middle cerebral arteries
}

\author{
Shiong Wen Low, FRCS, ${ }^{1}$ Kejia Teo, MRCS, ${ }^{1}$ Sein Lwin, FRCS, ${ }^{1}$ Leonard L. L. Yeo, MRCP, ${ }^{2}$ \\ Prakash R. Paliwal, MRCP, ${ }^{2}$ Aftab Ahmad, MRCP, ${ }^{2}$ Arvind K. Sinha, MD, ${ }^{3}$ Hock Luen Teoh, MRCP, ${ }^{2}$ \\ Lily Y. H. Wong, BN, ${ }^{2}$ Vincent F. Chong, FRCR, ${ }^{3}$ Raymond C. S. Seet, MRCP, ${ }^{2}$ \\ Bernard P. L. Chan, MD, ${ }^{2}$ Tseng Tsai Yeo, FRACS, ${ }^{1}$ Ning Chou, FRCS, ${ }^{1}$ and Vijay K. Sharma, MD ${ }^{2,4}$ \\ 'Department of Surgery, ${ }^{2}$ Division of Neurology, and ${ }^{3}$ Department of Diagnostic Imaging, National University Hospital System, \\ Singapore; and ${ }^{4}$ YLL School of Medicine, National University of Singapore, Singapore
}

\begin{abstract}
OBJECT Both the older and the recent extracranial-intracranial (EC-IC) bypass trials for symptomatic carotid occlusion failed to demonstrate a reduction in stroke recurrence. However, the role of superficial temporal artery (STA)-middle cerebral artery (MCA) bypass in patients with symptomatic intracranial stenoocclusive disease has been rarely evaluated. The authors evaluated serial changes in various cerebral hemodynamic parameters in patients with severe stenoocclusive disease of the intracranial internal carotid artery (ICA) or middle cerebral artery (MCA) and impaired cerebral vasodilatory reserve (CVR), treated by STA-MCA bypass surgery or medical treatment.
\end{abstract}

METHODS Patients with severe stenoocclusive disease of the intracranial ICA or MCA underwent transcranial Doppler (TCD) ultrasonography and CVR assessment using the breath-holding index (BHI). Patients with impaired $\mathrm{BHI}(<0.69)$ were further evaluated with acetazolamide-challenge technitium-99m hexamethylpropyleneamine oxime (99mTc HMPAO) SPECT. STA-MCA bypass surgery was offered to patients with impaired CVR on SPECT. All patients underwent TCD and SPECT at $4 \pm 1$ months and were followed up for cerebral ischemic events.

RESULTS A total of 112 patients were included. This total included 73 men, and the mean age of the entire study population was 56 years (range 23-78 years). ${ }^{99 \mathrm{~m} T C}$ HMPAO SPECT demonstrated impaired CVR in 77 patients (69\%). Of these 77 patients, 46 underwent STA-MCA bypass while 31 received best medical treatment. TCD and acetazolamidechallenge ${ }^{99 m T C}$ HMPAO SPECT repeated at $4 \pm 1$ months showed significant improvement in the STA-MCA bypass group. During a mean follow-up of 34 months (range 18-39 months), only 6 (13\%) of 46 patients in the bypass group developed cerebral ischemic events, as compared with 14 (45\%) of 31 patients receiving medical therapy (absolute risk reduction $32 \%, p=0.008)$.

CONCLUSIONS STA-MCA bypass surgery in carefully selected patients with symptomatic severe intracranial stenoocclusive disease of the intracranial ICA or MCA results in significant improvement in hemodynamic parameters and reduction in stroke recurrence.

http://thejns.org/doi/abs/10.3171/2014.11.JNS141553

KEY WORDS acute ischemic stroke; intracranial atherosclerosis; cerebral vasodilatory reserve; SPECT; external carotid-internal carotid bypass; superficial temporal artery; middle cerebral artery; bypass; vascular disorders

\footnotetext{
ABBREVIATIONS BHI = breath-holding index; CVR = cerebral vasodilatory reserve; EC-IC = extracranial-intracranial; HMPAO = hexamethylpropyleneamine oxime; ICA = internal carotid artery; $\mathrm{MCA}=$ middle cerebral artery; $\mathrm{STA}=$ superficial temporal artery; $\mathrm{TCD}=$ transcranial Doppler. SUBMITTED July 4, 2014. ACCEPTED November 25, 2014. INCLUDE WHEN CITING Published online May 29, 2015; DOI: 10.3171/2014.11.JNS141553.

DISCLOSURE Dr. Sharma received an individual research grant from the National Medical Research Council Singapore (no. NMRC/038/2008).
} 
$\mathrm{S}$ TENOOCCLUSIVE disease of the intracranial arteries accounts for $33 \%-54 \%$ of ischemic strokes among Asians. ${ }^{34}$ The risk of cerebral ischemic events in patients with intracranial stenosis is high despite the best medical therapy. ${ }^{13}$ The 1-year risk of ischemic stroke increases proportionately with the degree of stenosis, i.e., $11 \%-12 \%$ in patients with $>50 \%$ stenosis and $18 \%-23 \%$ when the stenosis is $>70 \%{ }^{4,14}$ Recent attempts at reducing this risk with intracranial stent placement for patients with severe stenosis (70\%-99\%) failed to show benefits as compared with "aggressive medical therapy." $\mathrm{Al}$ though both the older as well as the recent extracranialintracranial (EC-IC) bypass trials were conducted for patients with symptomatic occlusive disease of the cervical segment of the internal carotid artery (ICA), there were no significant benefits of surgery compared with "best medical therapy." 7,24

Artery-to-artery embolization and cerebral hemodynamic insufficiency are the 2 main mechanisms of cerebral ischemic events in patients with intracranial stenosis., ${ }^{9,16,25,30}$ Transcranial Doppler (TCD) ultrasonography monitoring can demonstrate a cerebral embolization by identifying the spontaneous microembolic signals in appropriate arterial branches distal to the stenoocclusive lesion ${ }^{19,22,28}$ and help in planning the appropriate antithrombotic treatment. ${ }^{20,37}$ Various compensatory collateral pathways in patients with severe intracranial stenosis can be evaluated noninvasively with CT angiography, ${ }^{32} \mathrm{MR}$ angiography, ${ }^{15}$ or TCD ultrasonography. ${ }^{31}$ Cerebral autoregulation helps in maintaining an adequate regional cerebral blood flow over a wide range of blood pressures by adjusting the diameter of the intracranial arterioles. ${ }^{21,22}$ Cerebral perfusion in regions distal to the intracranial stenosis may be normal at rest due to the compensatory vasodilatation. ${ }^{11,23}$ However, it may become insufficient in certain physiological circumstances due to a failed vasodilatory reserve and intracranial steal phenomenon (reversed Robin Hood syndrome). ${ }^{1}$ The assessment of cerebral hemodynamic insufficiency and cerebral vasodilatory reserve (CVR) has remained a complex issue. Various imaging techniques currently used to evaluate dynamic cerebral autoregulation and CVR include PET,2,35 dynamic first-pass perfusion CT, ${ }^{27}$ xenon-enhanced $\mathrm{CT},{ }^{10}$ perfusion-weighted MRI, ${ }^{33}$ and SPECT. ${ }^{5}$

In this study, we evaluated the cerebral hemodynamic status and CVR in patients with chronic and symptomatic severe stenoocclusive disease of the ICA or middle cerebral artery (MCA) with continuous TCD monitoring during voluntary breath-holding and SPECT with acetazolamide challenge. Patients with impaired CVR were offered superficial temporal artery (STA)-MCA bypass surgery. In addition to analyzing the cerebral ischemic events during the follow-up period, changes in the patients' cerebral hemodynamic patterns and CVR were also evaluated.

\section{Methods}

In this prospective study, consecutive patients with symptomatic and severe stenoocclusive disease of the intracranial ICA or MCA were recruited between February 2009 and May 2012. Our study included patients 21-80 years of age, with a history of transient ischemic attack or nondisabling stroke, involving the intracranial ICA or MCA within the past 3 months of presentation. Data were collected prospectively regarding the demographic characteristics, underlying risk factors, and other relevant associated diseases. All patients underwent a noncontrastenhanced CT scan of the head as the standard of care. Additional relevant imaging studies to diagnose the underlying pathogenic mechanism were performed according to the discretion of the attending stroke neurologist. We excluded patients with disabling stroke (modified Rankin Scale score of 3 or more), allergy to acetazolamide, stenoocclusive disease of the cervical ICA amenable to carotid endarterectomy or stent placement, and other active, advanced, untreatable medical conditions and markedly shortened expected life span. The study was approved by the ethics committee of the National University Health System, Singapore.

\section{Transcranial Doppler Ultrasonography}

All eligible patients were evaluated with diagnostic TCD for assessment of major intracranial arteries with the Nicolet-Viasys SONARA System (VIASYS Healthcare Inc.). Intracranial stenosis was diagnosed according to the established criteria. ${ }^{31}$ Patients in whom a long stenotic segment involved both the terminal ICA and proximal MCA were classified as having a stenoocclusive disease of the terminal ICA. Stenoocclusive disease of the ICA or MCA was considered severe $(>70 \%)$ according to the velocity criteria $^{38}$ and the presence of "blunted" flow spectra in the arterial segment distal to the stenosis. Importantly, the TCD diagnostic criteria for intracranial stenosis in our neurovascular laboratory have been validated against CT angiography. ${ }^{26}$

All study participants underwent continuous TCD monitoring for 40 minutes to exclude artery-to-artery embolization as the pathogenic mechanism for their symptoms. Patients with spontaneous TCD emboli were subjected to optimization of their antithrombotic medications and excluded from the study. Intracranial stenoses were confirmed in each patient by CT angiography, contrastenhanced MR angiography, or digital subtraction angiography.

\section{Assessment of CVR by TCD}

Bilateral TCD monitoring was performed during voluntary breath-holding according to a standard scanning protocol to evaluate the dynamic changes in blood flow velocities. We monitored arterial segments distal to the site of stenosis and the corresponding contralateral artery was used as the reference. CVR was assessed by the breathholding index (BHI) according to the well-established criteria. ${ }^{21}$ Briefly, after a clear demonstration by the sonographer, patients were asked to voluntarily stop breathing during a normal breathing pattern. A gasp, deep inhalation, or sigh were not allowed. Similarly, at the point of restarting breathing, patients were instructed to start without a violent inspiratory gasp or sigh. Breath holding for at least 30 seconds was considered appropriate. Patients unable to hold their breath for the required period were 
excluded from this study. The assessments were performed at least 3 times to validate the results and the highest $\mathrm{BHI}$ value was recorded. A paradoxical decrease in the mean flow velocity during voluntary breath holding reflected intracranial steal phenomenon (the so-called reversed Robin Hood syndrome). ${ }^{1}$ A BHI value less than 0.69 was considered to represent inadequate CVR. ${ }^{21}$

\section{Assessment of CVR by SPECT}

Patients with TCD-BHI values of less than 0.6 were further evaluated with acetazolamide-challenge Technitium$99 \mathrm{~m}$ hexamethylpropyleneamine oxime ( ${ }^{99 \mathrm{~m}} \mathrm{Tc}$ HMPAO) SPECT. After keeping the patient in a dark and quiet area for 30 minutes, SPECT and planar images were acquired with the intravenous injection of $732 \mathrm{MBq}$ of ${ }^{99 \mathrm{~m}} \mathrm{Tc}$ HMPAO. Scans were repeated within 3 to 7 days with acetazolamide challenge. Acetazolamide was injected intravenously at a dose of $20 \mathrm{mg} / \mathrm{kg}$ body weight, and 20 minutes later, patient received $732 \mathrm{MBq}$ of ${ }^{99 \mathrm{~m}} \mathrm{Tc}$ HMPAO. SPECT and planar images were acquired 20 minutes after the administration of ${ }^{99 \mathrm{~m} T c}$ HMPAO. Images were reconstructed in axial, sagittal, as well as coronal planes after corrections for the attenuation using transmission maps. All images were corrected for attenuation using Chang's method (uniform linear attenuation coefficient $0.12 / \mathrm{cm}$ ). Comparisons were made between the images obtained with and without acetazolamide to obtain the differences between the gamma-ray counts of 2 cerebral hemispheres to assess the CVR. A difference of more than $6 \%$ in the gamma-ray count between 2 hemispheres was defined as impaired CVR.

\section{STA-MCA Bypass Surgery}

Patients with significantly abnormal cerebral hemodynamic reserve were offered a cerebral revascularization procedure according to the recommendation of the stroke team, consisting of an attending stroke neurologist, an attending vascular surgeon, and an attending neuroradiologist. The current status of STA-MCA bypass surgery, especially in view of the recent clinical trial results, ${ }^{3,24}$ was explicitly explained to the patients and their relatives.

We performed a direct end-to-side anastomosis of a branch of the STA to a cortical branch of the MCA. The donor and recipient vessels chosen were approximately 1 $\mathrm{mm}$ in diameter. The surgery was performed through a frontotemporal scalp incision with preservation of the STA branches. The donor branch of the STA was dissected from the inner surface of the scalp flap. A small craniotomy centered approximately $6 \mathrm{~cm}$ from the external auditory canal exposed the distal MCA branches as they exited from the sylvian fissure. After selecting the suitable recipient artery, the overlying arachnoid and pia mater was opened and the vessel was prepared for anastomosis. Under microscopic visualization, an end-to-side anastomosis was performed with interrupted $10-0$ Prolene sutures. The craniotomy bone flap was placed back after removing a small edge of the bone to allow passage of the STA branch. The scalp was then closed in layers with vicryl and Prolene sutures. The method of bypass is represented in Fig. 1.

\section{Medical Therapy}

Patients who refused STA-MCA bypass surgery were managed with the best medical therapy, as determined by the treating neurologist. In general, the best medical therapy consisted of adequate control of diabetes mellitus (target glycated hemoglobin level $<7 \%$ ), blood pressure $(<$ $140 / 90 \mathrm{~mm} \mathrm{Hg})$ and low-density lipoprotein levels $(<2.6$ $\mathrm{mmol} / \mathrm{L}$ ). Antiplatelet therapy consisted of a single drug, i.e., $100 \mathrm{mg}$ of aspirin daily or $75 \mathrm{mg}$ of clopidogrel daily.

\section{Follow-Up}

All patients were followed up for the occurrence of any cerebral ischemic events. TCD-BHI and acetazolamide-challenge ${ }^{99 \mathrm{~m}} \mathrm{Tc}$ HMPAO SPECT were repeated in all patients after $4 \pm 1$ months to ascertain their CVR, to evaluate the natural history of the disease in the medically treated patients, and to evaluate changes in hemodynamic parameters in the surgical group.

\section{Statistical Analysis}

Statistical comparisons were performed between patients treated with STA-MCA bypass and best medical therapy in terms of various vascular risk factors, location of intracranial stenoocclusive disease, and various cerebral hemodynamic parameters. Dichotomous variables were compared with the chi-square test and continuous variables using 1-way ANOVA, or Kruskal-Wallis 1-way ANOVA by ranks as indicated. Post hoc comparisons between pairs of means were made in parametric and nonparametric ANOVA by means of the Tukey test and Wilcoxon rank-sum test, respectively. All patients were revaluated at $4 \pm 1$ months for clinical events and various hemodynamic parameters using TCD and SPECT. Statistical analyses were performed using the SPSS statistical software package (version 19.0 for Windows, SPSS Inc).

\section{Results}

Of the 112 patients with severe intracranial stenosis and inadequate CVR by our TCD criteria, impaired CVR on acetazolamide-challenge ${ }^{99 \mathrm{~m} T c}$ HMPAO SPECT was detected in 77 cases (69\%). This total included 73 men, and the mean age of the entire study population was 56 years (range 23-78 years). Forty-six of these 77 patients underwent STA-MCA bypass, while 31 received the best medical treatment. The two groups were well matched in terms of age, sex, vascular risk factors, and location of intracranial stenosis (Table 1). However, patients in the STA-MCA bypass group had significantly worse baseline cerebral hemodynamics on TCD as well as acetazolamide-challenge ${ }^{99 \mathrm{~m} T c}$ HMPAO SPECT imaging (Table 2). There were no perioperative complications. TCD and SPECT evaluations, repeated at $4 \pm 1$ months after the surgery, showed significant improvement in the cerebral hemodynamic parameters in the STA-MCA bypass group (Table 3). During a mean follow-up of 34 months (range 18-39 months), only $6(13 \%)$ of 46 patients in the bypass group developed cerebral ischemic events as compared with $14(45 \%)$ of 31 cases receiving medical therapy (absolute risk reduction $32 \%, \mathrm{p}=0.008$; Table 4). TCD and SPECT imaging characteristics in 1 of the patients are shown in Fig. 2. 


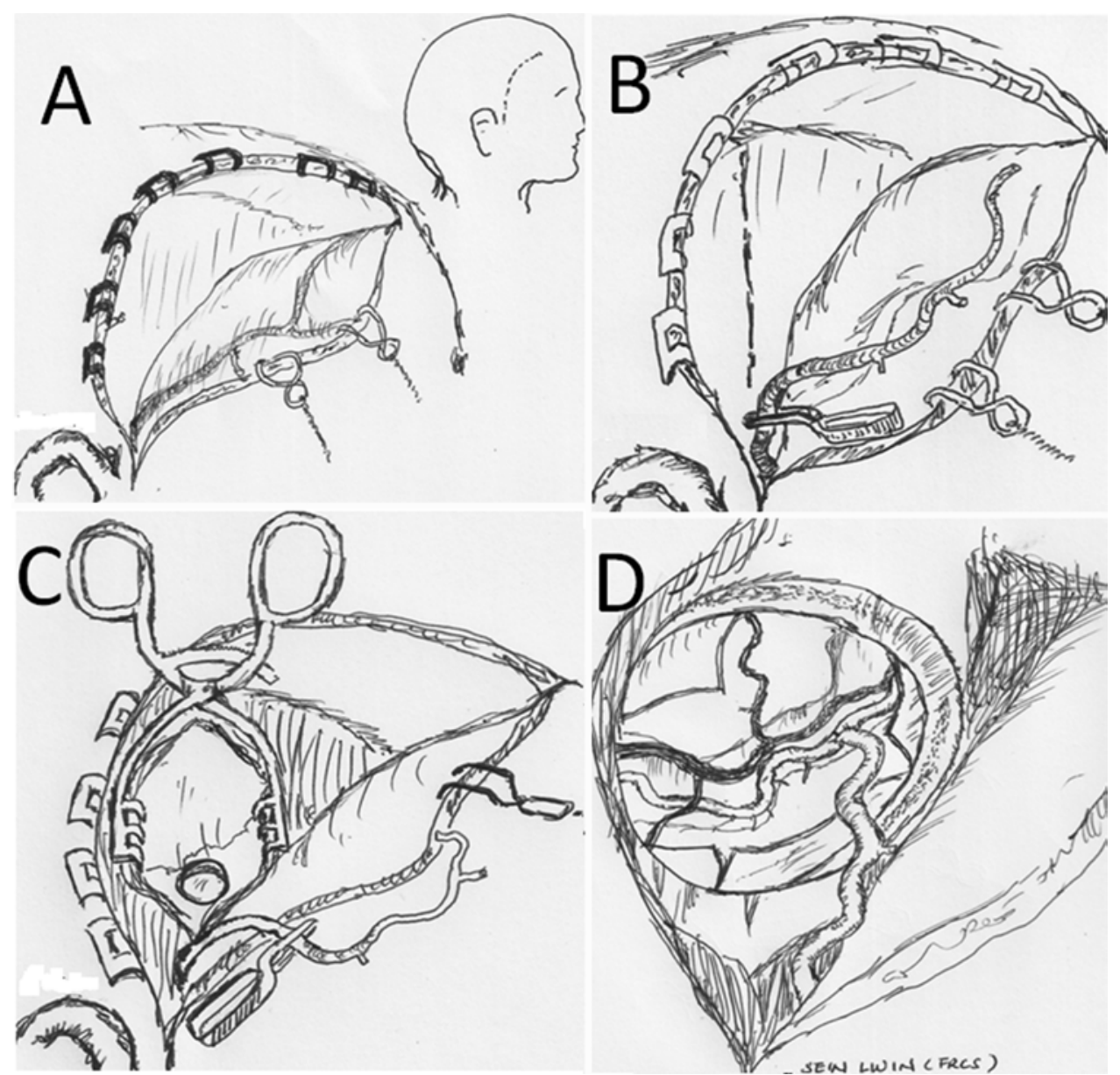

FIG. 1. Diagrams of the surgical technique of STA-MCA bypass surgery. The surgery was performed through a frontotemporal scalp incision with preservation of the STA branches (A). The donor and recipient vessels chosen are about $1 \mathrm{~mm}$ in diameter. The donor branch of the STA was dissected from the inner surface of the scalp flap (B and C). A direct end-to-side anastomosis between a branch of the STA to a cortical branch of the MCA was performed after selecting the suitable recipient artery (D). The craniotomy bone flap was replaced after removing a small edge of the bone to allow passage of the STA branch. The scalp was then closed in layers. Copyright Sein Lwin. Published with permission.

TABLE 1. Baseline characteristics of patients with impaired CVR on acetazolamide-challenge ${ }^{99 \mathrm{~m} T c}$ HMPAO SPECT $(n=77)$

\begin{tabular}{lccc}
\hline \multicolumn{1}{c}{ Variable } & $\begin{array}{c}\text { STA-MCA } \\
\text { Bypass (\%) }\end{array}$ & $\begin{array}{c}\text { Best Medical } \\
\text { Therapy (\%) }\end{array}$ & p Value \\
\hline No. of patients & 46 & 31 & \\
\hline Mean age \pm SD (yrs) & $56 \pm 11$ & $56 \pm 11$ & 0.242 \\
\hline Males & $28(60.9)$ & $20(64.5)$ & 0.327 \\
\hline Hypertension & $31(67.4)$ & $22(71)$ & 0.431 \\
\hline Diabetes mellitus & $12(26.1)$ & $9(29)$ & 0.331 \\
\hline Hypercholesterolemia & $28(60.9)$ & $18(58.1)$ & 0.425 \\
\hline Coronary heart disease & $7(15.2)$ & $7(22.6)$ & 0.132 \\
\hline $\begin{array}{l}\text { Obstructive sleep apnea syn- } \\
\text { drome }\end{array}$ & $26(56.5)$ & $18(58.1)$ & 0.762 \\
\hline Early morning headache & $24(52.2)$ & $15(48.4)$ & 0.513 \\
\hline $\begin{array}{l}\text { Intracranial ICA stenoocclusive } \\
\text { disease }\end{array}$ & $26(56.5)$ & $16(51.6)$ & 0.331 \\
\hline MCA stenosis & $20(43.5)$ & $15(48.4)$ & 0.412 \\
\hline
\end{tabular}

\section{Discussion}

Our study shows that STA-MCA bypass in carefully selected patients with severe stenoocclusive disease of the intracranial ICA or MCA improves cerebral hemodynamic parameters. Furthermore, this bypass surgery is beneficial for secondary prevention of cerebral ischemic events.

Our findings are consistent with some of the previous reports. ${ }^{12,17,29}$ Although the EC-IC bypass trials were conducted for patients with symptomatic ICA stenoocclusive disease, they failed to show the benefit of surgery over the "best medical therapy." 24,35 Similar failures were noted in a recent clinical trial of intracranial stent placement for patients with severe (70\%-99\%) intracranial stenosis. ${ }^{3}$ This trial failed due to unacceptably high rates of periprocedural complications and "lower than expected" rates of primary end points with "aggressive medical therapy." Although the recent intracranial stenting ${ }^{3}$ and EC-IC bypass surgery ${ }^{24}$ trials cited advances in the "best medical therapy" as one of the main reasons for their respective failures, the annual rates of cerebral ischemic events in ex- 
TABLE 2. Baseline TCD ultrasonographic and ${ }^{99 \mathrm{~m} T C}$ HMPAO SPECT parameters in patients with impaired CVR on acetazolamide-challenge ${ }^{99 m T C ~ H M P A O-S P E C T ~}(n=77)$

\begin{tabular}{|c|c|c|c|}
\hline Variable & STA-MCA Bypass $(n=46)$ & Best Medical Therapy $(n=31)$ & $\mathrm{p}$ Value \\
\hline Median $\mathrm{BH}$ of affected $\mathrm{MCA}^{*}(\mathrm{IQR})$ & $-0.05(0.49)$ & $0.32(0.59)$ & $<0.001 \dagger$ \\
\hline Median $\mathrm{BHI}$ of nonaffected $\mathrm{MCA}^{*}(\mathrm{IQR})$ & $1.09(0.40)$ & $1.20(0.59)$ & 0.584 \\
\hline Presence of intracranial steal on TCD (\%) & $23(50)$ & $8(25.8)$ & 0.013 \\
\hline Median \% TCD steal magnitude (IQR) & $4(18)$ & $0(12)$ & $0.001 \dagger$ \\
\hline Failed vasodilatory reserve on SPECT (\%) & $45(97.8)$ & $11(35.5)$ & $<0.001 \ddagger$ \\
\hline $\begin{array}{l}\text { Median net reduction in perfusion after acetazolamide } \\
\text { challenge (IQR) }\end{array}$ & $14(7)$ & $2(10)$ & $<0.001 \dagger$ \\
\hline $\begin{array}{l}\text { IQR = interquartile range. } \\
\text { * Lowest BHI value documented between } 2 \text { MCAs. } \\
\dagger \text { Using the Mann-Whitney U-test. } \\
\ddagger \text { Using the Fisher's exact test. }\end{array}$ & & & \\
\hline
\end{tabular}

cess of $10 \%{ }^{3,24}$ with the "best" medical therapy cannot be considered as acceptable. Importantly, these trial results are strong reminders for improving the methods of selecting patients who are most likely to benefit from intracranial stent placement or bypass surgery, as well as making these interventions safer.

Although clinical symptoms should be considered the gold standard for selecting patients for various interventional procedures, clinical judgments can be very subjective and do not differentiate between the "embolic" and "hemodynamic" causes of cerebral ischemia. Most of the previous studies have reported changes in cerebral hemodynamic parameters after EC-IC bypass surgery for patients with severe stenoocclusive disease of the cervical ICA. Schmiedek et al. assessed the CVR by measuring brain blood flow at rest and after acetazolamide infusion in patients with cervical ICA occlusions using Xe133 SPECT and reported significantly reduced CVR in patients with insufficient collateral circulation. ${ }^{29}$ These authors reevaluated CVR in their patients after EC-IC bypass and observed considerable postoperative improvement in response to the acetazolamide challenge. Similar improvements were reported on PET studies of oxygen extraction fraction by Powers et al. in the recently concluded EC-IC bypass trial. ${ }^{24}$ Most of the literature regarding intracranial stenoocclusive disease and changes in cerebral hemodynamics after EC-IC bypass surgery pertains to moyamoya disease in pediatric patients. Only a few studies have evaluated the impact of EC-IC bypass on hemodynamic parameters among adults. ${ }^{29}$ Kohno et al. reported the hemodynamic improvements using Xe-
133 SPECT in adult patients with moyamoya disease after EC-IC bypass. ${ }^{18}$ We strongly believe that the pathogenesis of moyamoya disease is very different as compared with atherosclerotic disease and hence excluded patients with moyamoya disease from our study. Therefore, the data from EC-IC bypass on patients with moyamoya disease may not be directly applicable to the atherosclerotic disease of intracranial arteries. However, data on adults with severe intracranial atherosclerotic stenoocclusive disease are limited..$^{18}$

One of the important findings of our study is the improvement in various cerebral hemodynamic parameters on TCD as well as acetazolamide-challenge SPECT in adult patients with symptomatic and severe stenoocclusive disease of the intracranial ICA or MCA. The improvement in cerebral hemodynamic parameters in our patients was associated with significant reduction in cerebral ischemic events during the follow-up period (absolute risk reduction $32 \%, p=0.008)$. Interestingly, EC-IC bypass surgery resulted in significant improvement in various cognitive parameters as compared with matched controls in a pilot study of 9 cases. $^{6}$

Another interesting observation in our study was the high prevalence of early morning headache. Almost half of our patients confessed of a dull, aching, vaguely defined headache upon waking up in the morning that disappeared within a couple of hours on its own. Almost all the cases presenting with early morning headache were found to have obstructive sleep apnea of various grades of severity. We hypothesized that relative hypercapnia due to obstructive sleep apnea or sleep-related hypoventilation

TABLE 3. Change of TCD and SPECT parameters in the STA-MCA bypass group $(n=46)$

\begin{tabular}{lcccc}
\hline \multicolumn{1}{c}{ Variable } & Before Bypass & After Bypass & Change & p Value \\
\hline Median BHI of affected MCA (IQR) & $-0.05(0.49)$ & $1.10(0.60)$ & $1.10(0.60)$ & $<0.001^{*}$ \\
\hline Median BHI of nonaffected MCA (IQR) & $1.09(0.40)$ & $1.00(0.45)$ & $0.00(0.52)$ & $0.774^{*}$ \\
\hline Failed CVR on SPECT (\%) & $45(97.8)$ & $9(19.6)$ & $\mathrm{NA}$ & $<0.001^{* *}$ \\
\hline $\begin{array}{l}\text { NA }=\text { not applicable } \\
* \text { by Wilcoxon signed-rank test; }\end{array}$ & & & & \\
${ }^{* *}$ by McNemar's test & & & &
\end{tabular}


TABLE 4. Recurrent stroke and new-onset early morning headache during the follow-up period of 27 months (range 8-38 months)

\begin{tabular}{lccc}
\hline \multicolumn{1}{c}{ Variable } & $\begin{array}{c}\text { STA-MCA } \\
\text { Bypass } \\
(\mathrm{n}=46)\end{array}$ & $\begin{array}{c}\text { Best Medical } \\
\text { Therapy }(\mathrm{n}=31)\end{array}$ & $\mathrm{p}$ Value \\
\hline Recurrent stroke (\%) & $6(13)$ & $14(45.2)$ & 0.008 \\
\hline Early morning headache (\%) & $4(8.7)$ & $13(41.9)$ & 0.005 \\
\hline
\end{tabular}

caused prolonged vasodilatation of the meningeal collaterals, and was the cause of their early morning headaches. These headaches disappeared in the majority of our EC-IC bypass surgery patients.

Certain limitations of our study need acknowledgment. First, although this was a prospective study, the number of patients included in the study may still be considered too small to draw definitive conclusions. Second, the lack of randomization is an important limitation of our study. Selection bias for surgery may not be excluded reliably, and the differences between the longitudinal hemodynamic parameters in the 2 groups may be influenced by this confounder. Finally, the use of SPECT in our study may draw some criticism. Positron emission tomography is considered the gold standard for estimating CVR. However, PET is expensive and not widely available. Blood flow reserve as assessed by brain SPECT correlates well with the oxygen extraction rates measured by PET. Therefore SPECT can be employed reliably for evaluating brain perfusion and blood flow reserve. Furthermore, the acetazolamide challenge adds to the dynamic nature of the test and makes it more reliable to assess the hemodynamic reserve in the brain. ${ }^{8}$ Intravenously administered acetazolamide induces marked dilation of cerebral vessels, thus increasing both cerebral blood flow and cerebral blood volume. Reduced acetazolamide reactivity represents Stage II hemodynamic failure as demonstrated and used in various PET studies. ${ }^{36}$ Although difficult to substantiate, our approach of assessing CVR through a dynamic challenge with acetazolamide might have helped in achieving a better selection of patients at high risk of developing recurrent cerebral ischemia. Oxygen extraction fraction on PET imaging was used in the recent Carotid Occlusion Surgery Study to select patients for STA-MCA bypass. ${ }^{24}$ We hypothesize that it measures only the static component of CVR and that such an approach might have led to an unnecessary bypass surgery in some patients. Vasodilatory challenge induced by acetazolamide during SPECT helps in identification of the reversible hemodynamic disturbances, and this approach
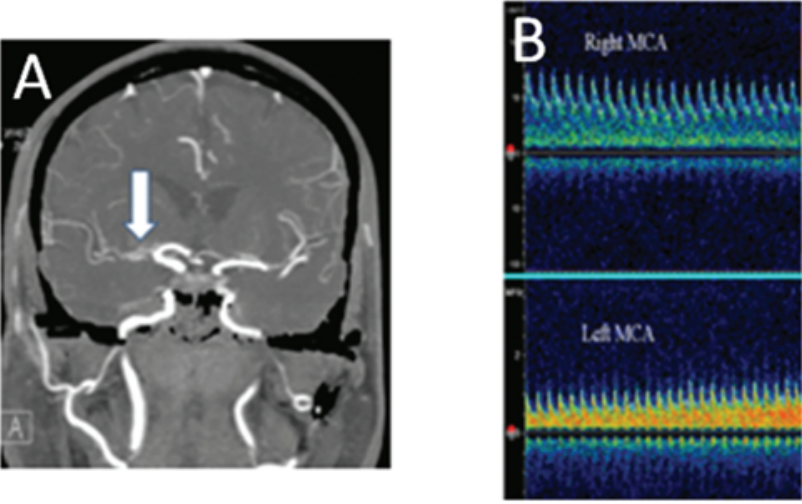

Baseline

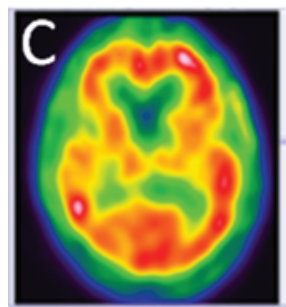

Right $44 \%$

Left $56 \%$

Left $72 \%$

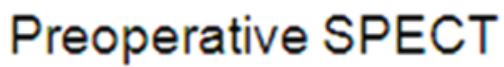

TCD Breathholding index

Right $M C A=$ exhausted with reversed Robin Hood syndrome, steal magnitude $23 \%$ Left MCA $=0.92$

FIG. 2. Imaging findings in a 43-year-old patient with symptomatic right MCA stenoocclusive disease. Coronal CT angiography (A) demonstrated a severe stenoocclusive disease of the right proximal MCA (arrow). TCD monitoring for vasomotor reactivity estimation during voluntary breath holding (B) showed normal flow acceleration in the left MCA. However, a paradoxical reduction of flow velocities was noted in the right MCA, suggestive of an exhausted CVR and reversed Robin Hood syndrome. Acetazolamide-challenge SPECT imaging (C and D) confirmed the findings of reversed Robin Hood syndrome that showed complete normalization (E and F) 4 months after STA-MCA bypass surgery. Figure is available in color online only. 
appears to be better for identifying patients who benefit most from a revascularization procedure.

\section{Conclusions}

In this study we demonstrate that STA-MCA bypass surgery in carefully selected patients with symptomatic severe intracranial stenoocclusive disease results in significant improvement in hemodynamic parameters and reduction in stroke recurrence.

\section{References}

1. Alexandrov AV, Sharma VK, Lao AY, Tsivgoulis G, Malkoff MD, Alexandrov AW: Reversed Robin Hood syndrome in acute ischemic stroke patients. Stroke 38:3045-3048, 2007

2. Baron JC, Bousser MG, Rey A, Guillard A, Comar D, Castaigne P: Reversal of focal "misery-perfusion syndrome" by extra-intracranial arterial bypass in hemodynamic cerebral ischemia. A case study with $15 \mathrm{O}$ positron emission tomography. Stroke 12:454-459, 1981

3. Chimowitz MI, Lynn MJ, Derdeyn CP, Turan TN, Fiorella D, Lane BF, et al: Stenting versus aggressive medical therapy for intracranial arterial stenosis. N Engl J Med 365:993-1003, 2011

4. Chimowitz MI, Lynn MJ, Howlett-Smith H, Stern BJ, Hertzberg VS, Frankel MR, et al: Comparison of warfarin and aspirin for symptomatic intracranial arterial stenosis. $\mathbf{N}$ Engl J Med 352:1305-1316, 2005

5. Cikrit DF, Dalsing MC, Harting PS, Burt RW, Lalka SG, Sawchuk AP, et al: Cerebral vascular reactivity assessed with acetazolamide single photon emission computer tomography scans before and after carotid endarterectomy. Am J Surg 174:193-197, 1997

6. Dong Y, Teoh HL, Chan BP, Ning C, Yeo TT, Sinha AK, et al: Changes in cerebral hemodynamic and cognitive parameters after external carotid-internal carotid bypass surgery in patients with severe steno-occlusive disease: a pilot study. J Neurol Sci 322:112-116, 2012

7. The EC/IC Bypass Study Group: Failure of extracranialintracranial arterial bypass to reduce the risk of ischemic stroke. Results of an international randomized trial. N Engl J Med 313:1191-1200, 1985

8. Garrett MC, Komotar RJ, Starke RM, Merkow MB, Otten ML, Sciacca RR, et al: The efficacy of direct extracranialintracranial bypass in the treatment of symptomatic hemodynamic failure secondary to athero-occlusive disease: a systematic review. Clin Neurol Neurosurg 111:319-326, 2009

9. Gibbs JM, Wise RJS, Leenders KL, Jones T: Evaluation of cerebral perfusion reserve in patients with carotid-artery occlusion. Lancet 1:310-314, 1984

10. Gur D, Good WF, Wolfson SK Jr, Yonas H, Shabason L: In vivo mapping of local cerebral blood flow by xenon-enhanced computed tomography. Science 215:1267-1268, 1982

11. Harper AM, Glass HI: Effect of alterations in the arterial carbon dioxide tension on the blood flow through the cerebral cortex at normal and low arterial blood pressures. J Neurol Neurosurg Psychiatry 28:449-452, 1965

12. Ishikawa T, Houkin $\mathrm{K}$, Abe $\mathrm{H}$, Isobe $\mathrm{M}$, Kamiyama $\mathrm{H}$ : Cerebral haemodynamics and long-term prognosis after extracranial-intracranial bypass surgery. J Neurol Neurosurg Psychiatry 59:625-628, 1995

13. Kasner SE: Natural history of symptomatic intracranial arterial stenosis. J Neuroimaging 19 (Suppl 1):20S-21S, 2009

14. Kasner SE, Chimowitz MI, Lynn MJ, Howlett-Smith H, Stern BJ, Hertzberg VS, et al: Predictors of ischemic stroke in the territory of a symptomatic intracranial arterial stenosis. Circulation 113:555-563, 2006
15. Katz DA, Marks MP, Napel SA, Bracci PM, Roberts SL: Circle of Willis: evaluation with spiral CT angiography, MR angiography, and conventional angiography. Radiology 195:445-449, 1995

16. Kistler JP, Ropper AH, Heros RC: Therapy of ischemic cerebral vascular disease due to atherothrombosis (1). N Engl J Med 311:27-34, 1984

17. Klijn CJ, Kappelle LJ, van der Zwan A, van Gijn J, Tulleken CA: Excimer laser-assisted high-flow extracranial/intracranial bypass in patients with symptomatic carotid artery occlusion at high risk of recurrent cerebral ischemia: safety and long-term outcome. Stroke 33:2451-2458, 2002

18. Kohno K, Oka Y, Kohno S, Ohta S, Kumon Y, Sakaki S: Cerebral blood flow measurement as an indicator for an indirect revascularization procedure for adult patients with moyamoya disease. Neurosurgery 42:752-758, 1998

19. Levi CR, O’Malley HM, Fell G, Roberts AK, Hoare MC, Royle JP, et al: Transcranial Doppler detected cerebral microembolism following carotid endarterectomy. High microembolic signal loads predict postoperative cerebral ischaemia. Brain 120:621-629, 1997

20. Markus HS, Droste DW, Kaps M, Larrue V, Lees KR, Siebler M, et al: Dual antiplatelet therapy with clopidogrel and aspirin in symptomatic carotid stenosis evaluated using Doppler embolic signal detection: the Clopidogrel and Aspirin for Reduction of Emboli in Symptomatic Carotid Stenosis (CARESS) trial. Circulation 111:2233-2240, 2005

21. Markus HS, Harrison MJ: Estimation of cerebrovascular reactivity using transcranial Doppler, including the use of breath-holding as the vasodilatory stimulus. Stroke 23:668673, 1992

22. Markus HS, MacKinnon A: Asymptomatic embolization detected by Doppler ultrasound predicts stroke risk in symptomatic carotid artery stenosis. Stroke 36:971-975, 2005

23. Powers WJ: Cerebral hemodynamics in ischemic cerebrovascular disease. Ann Neurol 29:231-240, 1991

24. Powers WJ, Clarke WR, Grubb RL Jr, Videen TO, Adams HP Jr, Derdeyn CP: Extracranial-intracranial bypass surgery for stroke prevention in hemodynamic cerebral ischemia: the Carotid Occlusion Surgery Study randomized trial. JAMA 306:1983-1992, 2011

25. Powers WJ, Press GA, Grubb RL Jr, Gado M, Raichle ME: The effect of hemodynamically significant carotid artery disease on the hemodynamic status of the cerebral circulation. Ann Intern Med 106:27-34, 1987

26. Rathakrishnan R, Berne YI, Quek KK, Hong CS, Ong BK, Chan BP, et al: Validation of transcranial Doppler with CT angiography in cerebral ischaemia: a preliminary pilot study in Singapore. Ann Acad Med Singapore 37:402-405, 2008

27. Reichenbach JR, Röther J, Jonetz-Mentzel L, Herzau M, Fiala A, Weiller C, et al: Acute stroke evaluated by time-to-peak mapping during initial and early follow-up perfusion CT studies. AJNR Am J Neuroradiol 20:1842-1850, 1999

28. Ringelstein EB, Droste DW, Babikian VL, Evans DH, Grosset DG, Kaps M, et al: Consensus on microembolus detection by TCD. Stroke 29:725-729, 1998

29. Schmiedek P, Piepgras A, Leinsinger G, Kirsch CM, Einhüpl $\mathrm{K}$ : Improvement of cerebrovascular reserve capacity by ECIC arterial bypass surgery in patients with ICA occlusion and hemodynamic cerebral ischemia. J Neurosurg 81:236-244, 1994

30. Schroeder T: Cerebrovascular reactivity to acetazolamide in carotid artery disease. Enhancement of side-to-side CBF asymmetry indicates critically reduced perfusion pressure. Neurol Res 8:231-236, 1986

31. Sharma VK, Wong KSL: Intracranial stenosis, in Alexandrov V (ed): Cerebrovascular Ultrasound in Stroke Prevention and Treatment, ed 2. New York: Wiley-Blackwell, 2011, pp 228-239 
32. Skutta B, Fürst G, Eilers J, Ferbert A, Kuhn FP: Intracranial stenoocclusive disease: double-detector helical CT angiography versus digital subtraction angiography. AJNR Am J Neuroradiol 20:791-799, 1999

33. Sorensen AG, Buonanno FS, Gonzalez RG, Schwamm LH, Lev MH, Huang-Hellinger FR, et al: Hyperacute stroke: evaluation with combined multisection diffusion-weighted and hemodynamically weighted echo-planar MR imaging. Radiology 199:391-401, 1996

34. Suri MF, Johnston SC: Epidemiology of intracranial stenosis. J Neuroimaging 19 (Suppl 1):11S-16S, 2009

35. Ter-Pogossian MM, Herscovitch P: Radioactive oxygen-15 in the study of cerebral blood flow, blood volume, and oxygen metabolism. Semin Nucl Med 15:377-394, 1985

36. Vorstrup S: Tomographic cerebral blood flow measurements in patients with ischemic cerebrovascular disease and evaluation of the vasodilatory capacity by the acetazolamide test. Acta Neurol Scand Suppl 114:1-48, 1988

37. Wong KS, Chen C, Fu J, Chang HM, Suwanwela NC, Huang YN, et al: Clopidogrel plus aspirin versus aspirin alone for reducing embolisation in patients with acute symptomatic cerebral or carotid artery stenosis (CLAIR study): a randomised, open-label, blinded-endpoint trial. Lancet Neurol 9:489-497, 2010

38. Zhao L, Barlinn K, Sharma VK, Tsivgoulis G, Cava LF,
Vasdekis SN, et al: Velocity criteria for intracranial stenosis revisited: an international multicenter study of transcranial Doppler and digital subtraction angiography. Stroke 42:3429-3434, 2011

\section{Author Contributions}

Conception and design: Sharma, Lwin, Paliwal, Sinha. Acquisition of data: Sharma, Low, Teo, Lwin, Yeo, Paliwal, Ahmad, Sinha, Teoh, Wong, Chou. Analysis and interpretation of data: Sharma, Yeo, Ahmad, Sinha, Chong, Chou. Drafting the article: Sharma, Low, Lwin. Critically revising the article: all authors. Reviewed submitted version of manuscript: all authors. Approved the final version of the manuscript on behalf of all authors: Sharma. Statistical analysis: Sharma. Administrative/ technical/material support: Sharma. Study supervision: Sharma.

\section{Correspondence}

Vijay K. Sharma, Division of Neurology, Department of Medicine, 5 Lower Kent Ridge Rd., National University Hospital, Singapore 119074, Republic of Singapore.email: drvijay@ singnet.com.sg. 